\title{
Reforma tributaria para el desarrollo humano en Centroamérica
}

\author{
Manuel R. Agosin, Alberto Barreix, Juan Carlos Gómez \\ Sabaini y Roberto Machado
}

Manuel R. Agosin,

Asesor Económico Regional para México,

Centroamérica, Rep. Dominicana y Haití,

Banco Interamericano de Desarrollo (BID).

Profesor Titular, Departamento de

Economía,

Universidad de Chile

• manuelag@iadb.org

Alberto Barreix,

Economista Senior, Departamento de Integración y Programas Regionales, BID

• albertoba@iadb.org

Juan Carlos Gómez Sabaini,

Profesor,

Universidad Nacional de Buenos Aires.

Consultor internacional

• gsabaini@ciudad.com.ar

Roberto Machado,

Economista de Proyecto,

Departamento Regional de Operaciones 2, BID

•robertom@contractual.iadb.org

os Estados centroamericanos sólo recaudan el 13,5\% del producto interno bruto en ingresos tributarios. La falta de recursos resultante hace que el gasto público sea insuficiente y de baja calidad y genere déficit fiscales crónicos que son financiados mediante endeudamiento. En el 2003 los intereses alcanzaron, en promedio, al 18\% de los ingresos impositivos. En estas economías abiertas que necesitan afianzar la competitividad internacional de sus empresas, la política fiscal se vuelve el factor crítico para financiar la infraestructura física y social requerida y, a la vez, combatir los altos niveles de pobreza que todavía afectan a cerca del $40 \%$ de la población. Por lo tanto, para el desarrollo económico de Centroamérica es indispensable efectuar reformas de segunda generación que modernicen los sistemas tributarios y que recauden en promedio unos cuatro puntos porcentuales más de PIB. 


\section{I \\ Motivando la reforma tributaria en Centroamérica}

En Centroamérica es imprescindible una reforma tributaria si se quiere alcanzar el tipo de sociedad a la que aspiran los centroamericanos, es decir, una con más crecimiento y equidad. Son varias las motivaciones para promover una reforma de este tipo. La primera, y más importante, es que los Estados centroamericanos son demasiado pequeños y vulnerables como para proveer los bienes públicos que se necesitan para incentivar el crecimiento económico y mejorar los niveles de bienestar de sus poblaciones. El hecho de que la recaudación tributaria media en la subregión haya estado alrededor del 13,5\% del PIB en los últimos años explica fácilmente por qué estos países no están en condiciones de mejorar los niveles de educación y salud, de construir la infraestructura necesaria para el desarrollo y de proveer la seguridad jurídica y ciudadana que requiere la inversión privada.

La segunda motivación es que todos los países centroamericanos tienen altas cargas de deuda pública acumuladas durante años de déficit fiscales crónicos. Por lo tanto, necesitan acrecentar la recaudación para que los gobiernos puedan generar superávit primarios (balances antes de los intereses sobre la deuda) que permitan ubicar la deuda pública en un nivel sostenible a largo plazo.

La tercera es que los cambios en los patrones de inserción internacional de la subregión exigirán profundas reformas en los sistemas tributarios. Cuando entre en vigencia el Tratado de Libre Comercio (TLC) entre Centroamérica y Estados Unidos, ${ }^{1}$ se producirá una caída importante en la recaudación por concepto de derechos de importación, que habrá que recuperar a través de otras fuentes tributarias.

Por otra parte, el hecho de que todos los países de la región hayan adherido a la Organización Mundial del Comercio (OMC) implica que deberán acatar las decisiones de dicho organismo. La que tendrá mayor relevan-

$\square$ Este artículo se basa en los análisis y conclusiones del libro Recaudar para crecer. Bases para la reforma tributaria en Centroamérica, editado por M. R. Agosin, A. Barreix y R. Machado y publicado por el Banco Interamericano de Desarrollo.

${ }^{1}$ Conocido también como CAFTA, por su sigla en inglés. cia para estos países es la eliminación, a más tardar a comienzos del 2010, de las exoneraciones del impuesto sobre la renta de las empresas en zonas francas, consideradas como un subsidio a las exportaciones y, por lo tanto, proscritas por el Acuerdo sobre Subvenciones y Medidas Compensatorias (Acuerdo SMC) emanado de la Ronda Uruguay que terminó a comienzos de 1995. $\mathrm{Al}$ aplicarla se deberá conciliar la necesidad de elevar la recaudación con la de no desincentivar la inversión en los sectores más dinámicos de la economía, para lo cual la tasa del impuesto sobre la renta de las empresas tendrá que ubicarse en niveles moderados. Para evitar el subsidio implícito, la OMC establece que las tasas dentro y fuera de las zonas francas deben igualarse. Esto podría redundar en pérdidas de recaudación, al disminuir las tasas para las empresas que no están ubicadas en esas zonas. Lo importante, entonces, va a ser cerrar otras vías de elusión de los impuestos sobre la renta de las empresas, como lo son las numerosas exoneraciones y los regímenes de depreciación acelerada. Las tasas pueden ser moderadas, pero las bases de tributación deben ser lo más amplias posibles.

El hecho de que se profundice la integración entre los países centroamericanos también tendrá efectos significativos en el diseño de la reforma de los sistemas tributarios. Las implicancias para los sistemas tributarios son obvias: sin una coordinación tributaria a nivel regional será imposible evitar el arbitraje tributario, lo que implicará pérdidas de producción y recaudación indeseadas para algunos países, y ganancias para otros. Baste mencionar el impuesto sobre la renta en las zonas francas. Sin una armonización subregional, los países tendrán mucho que perder: la competencia por inversiones obligará a una reducción innecesaria del impuesto sobre la renta de las sociedades en general, debido a que la norma de la omc es llegar a la igualdad de tratamiento de dicho impuesto en toda la economía.

Una cuarta motivación, que constituye otro reto para los sistemas tributarios de los países centroamericanos, es la necesidad de diseñar una estrategia de descentralización fiscal apropiada. Todos estos países han asignado prioridad a la descentralización, pero ninguno ha logrado aplicarla sin causar disminuciones de los recursos del gobierno central que atenten contra su 
desempeño. Los impuestos locales deben fortalecerse, en particular el impuesto predial que ahora genera recaudaciones muy modestas e inferiores a su potencial.

\section{Desarrollo humano y papel del gasto público social}

La premisa central de este trabajo es que el crecimiento económico y el desarrollo humano están íntimamente ligados por relaciones de múltiple causalidad. ${ }^{2}$ Por una parte, la hipótesis de que los aspectos centrales del desarrollo humano dependen del ingreso per cápita es generalmente aceptada. Por otra, la relación de causalidad también va desde el desarrollo humano al crecimiento sostenido. Este último requiere de un mínimo de educación en la fuerza de trabajo; sin ella, la productividad del trabajo es demasiado baja para hacer rentable la inversión privada. Algo similar puede decirse de la salud. Una población con mala salud se traduce en una fuerza de trabajo de baja productividad. Por lo tanto, la salud y la educación, aspectos centrales del desarrollo humano, son un fin en sí mismo, pero también un insumo esencial para el crecimiento.

A pesar de que los gobiernos centroamericanos han realizado importantes reformas económicas, el nivel de su gasto público social continúa siendo insuficiente. ${ }^{3}$ La recaudación tributaria en la subregión se halla entre el 10\% y el 14\% del PIB y los gastos públicos están entre el $10 \%$ y el $18 \%$ de él. ${ }^{4}$ Estas tasas son

\footnotetext{
${ }^{2}$ Usamos aquí el término "desarrollo humano" en la acepción que ha popularizado el Programa de las Naciones Unidas para el Desarrollo (PNUD). Los elementos que componen este término genérico son muy amplios e incluyen una alta esperanza de vida, una vida de buena calidad y con bajos índices de enfermedad, buenos indicadores de educación, participación ciudadana en las decisiones, igualdad de oportunidades, igualdad de género. En la concepción de Amartya Sen, el desarrollo humano es sinónimo de libertad: la capacidad de los individuos de vivir de la manera en que ellos eligen hacerlo (Sen, 1999). Por supuesto, el PIB per cápita es un indicador insoslayable del desarrollo humano, pero no es el único. Para evaluar los niveles de desarrollo humano de una nación es necesario ponderar un conjunto amplio de variables, tal como lo resume el PNUD en su Índice de Desarrollo Humano.

${ }^{3}$ Todos los países de la subregión han efectuado importantes liberalizaciones de sus mercados, privatizaciones de muchas empresas públicas y una apertura generalizada al comercio exterior. Véase una descripción de estos procesos en Agosin, Machado y Nazal (2004).

${ }^{4}$ Al corregir la subestimación del PIB en Nicaragua y Honduras. Este es un fenómeno bien conocido por los especialistas en la subregión. Respecto a dicha subestimación en Honduras, véase PNUD (2000, cap. 3). Las estimaciones realizadas por uno de los autores, basándose en una investigación de toda la información existente, indican que en Honduras y Nicaragua habría que corregir los PIB en al menos $40 \%$ y $70 \%$, respectivamente, para acercarlos a sus niveles efectivos. Después de varios años de trabajo, el Banco Central
}

bajas si se comparan con las que cabría esperar en países con las características estructurales de los centroamericanos.

Esta afirmación es el resultado de un análisis econométrico de la recaudación tributaria, de los gastos públicos totales y los gastos públicos en educación y en salud en el mundo como proporción del PIB, y de la ubicación relativa de los países de la región. Todas las variables fueron medidas a fines del decenio de 1990. Las diferencias entre países que presentan la recaudación y el gasto público se explican por la variación del PIB per cápita (en términos de paridad de poder de compra) y por el coeficiente de Gini de distribución del ingreso. A medida que aumenta el ingreso per cápita, también lo hacen la carga tributaria y el gasto público, ya que mientras más elevados sean los ingresos de un país, mayor será su capacidad para financiar gastos públicos y gastos sociales básicos. Asimismo, es dable esperar que la demanda de gastos públicos por parte de la población varíe en relación directa con el ingreso per cápita e inversa con la desigualdad en la distribución del ingreso. Esta última hipótesis asume que, mientras más igualitaria sea la distribución del ingreso, mayor será la influencia de las capas medias en las decisiones de política económica y social, y que son justamente estas últimas las que demandan servicios públicos sociales. Los resultados, que son consistentes con estas hipótesis, están consignados en el apéndice. ${ }^{5}$

$\mathrm{Al}$ interpolar en las ecuaciones estimadas los valores del PIB per cápita y el coeficiente de Gini para los cinco países del Mercado Común Centroamericano (МССA), se observa que en casi todos los casos los valores esperados de las cuatro variables fiscales son superiores a los valores observados. Esto indica que, efectivamente, incluso controlando por las características estructurales de las economías de Centroamérica, los Estados centroamericanos son pequeños. El gráfico 1 muestra los resultados para la recaudación tributaria.

de Nicaragua elevó en $63 \%$ su estimación del PIB en las revisiones de las cuentas nacionales efectuadas en el 2003. El Banco Central de Honduras aún no ha dado a conocer sus revisiones.

${ }^{5}$ Nótese que este esbozo teórico está en contradicción con el influyente modelo desarrollado por Alesina y Rodrik (1994), en el cual se postula que la recaudación tributaria es mayor mientras más desigual sea la distribución del ingreso. Dichos autores recurren a un modelo del votante mediano, en el que los votantes preferirán mayores impuestos mientras menores sean los acervos de capital físico y humano de la mayoría (justamente cuando la distribución del ingreso es más desigual). Sin embargo, los datos estadísticos no avalan esta teoría. Por el contrario, son congruentes con nuestras consideraciones teóricas. 
GRÁFICO 1

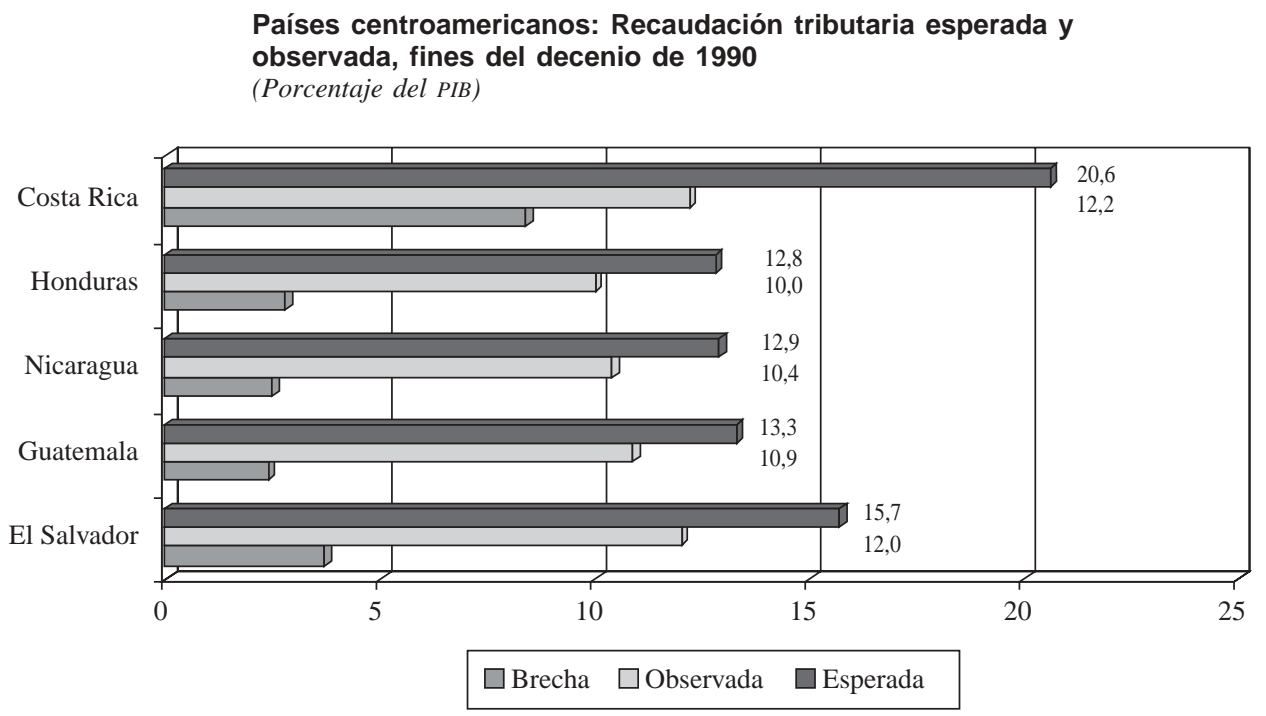

Fuente: Banco Mundial (2004); cifras oficiales nacionales y cálculos de los autores.

Llama la atención la fuerte discrepancia entre la carga tributaria esperada y la observada de Costa Rica. La recaudación observada costarricense a fines de la década de 1990 fue de apenas 12\% del PIB (ahora es algo más que el $13 \%$ ) y está por debajo del promedio para la región, en circunstancias de que su PIB per cápita es el más alto de Centroamérica y supera al de los dos países más pobres (Honduras y Nicaragua) por un factor de tres a cuatro (en dólares de paridad de poder de compra y ajustando por la subestimación del PIB en esos dos países). Al mismo tiempo, en Costa Rica el coeficiente de Gini de la distribución del ingreso es el más bajo de la región $(0,48$ en comparación con 0,63 en Guatemala y 0,58 en Nicaragua).

Esto lleva a concluir que, para llegar a la norma estimada por sus niveles de ingreso y la distribución del mismo, la recaudación tributaria debería aumentar en un $35 \%$, o en unos 4 puntos porcentuales del producto, que es la brecha media que se observa en el gráfico 1.

\section{Finanzas públicas: déficit, deuda y sosteni- bilidad}

Como se observa en el cuadro 1, en el 2004 el déficit fiscal de los países centroamericanos osciló entre 1,1 y $4,3 \%$ del PIB. Si bien el promedio de los déficit fue inferior al observado en el 2000, ellos todavía fueron altos, sobre todo si se considera que 2004 fue un año de crecimiento relativamente fuerte. Las cifras mues-
CUADRO 1

Centroamérica: Déficit del gobierno central y deuda pública

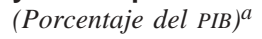

\begin{tabular}{|c|c|c|c|c|c|}
\hline & \multicolumn{2}{|c|}{$\begin{array}{c}\text { Déficit } \\
\text { fiscal }\end{array}$} & \multicolumn{2}{|c|}{$\begin{array}{c}\text { Deuda } \\
\text { externa }\end{array}$} & \multirow{2}{*}{$\begin{array}{l}\begin{array}{l}\text { Deuda } \\
\text { interna }\end{array} \\
2004^{\mathrm{b}}\end{array}$} \\
\hline & 1995 & 2000 & 2004 & $2004^{b}$ & \\
\hline Costa Rica & 4,0 & 2,9 & 3,0 & 21,1 & 38,7 \\
\hline El Salvador & 0,6 & 2,3 & 2,8 & 31,4 & 13,4 \\
\hline Guatemala & 0,7 & 1,8 & 1,1 & 16,0 & 9,4 \\
\hline Honduras & 3,1 & 5,7 & 3,5 & 61,6 & 7,5 \\
\hline Nicaragua $^{\mathrm{c}}$ & 11,0 & 11,0 & 4,3 & $76,0^{\mathrm{d}}$ & 41,3 \\
\hline
\end{tabular}

Fuente: Agosin, Barreix y Machado (2005).

a Para Honduras y Nicaragua, las cifras del PIB corresponden a las oficiales, lo que sobrestima los niveles de déficit y deuda pública.

b A fin de año.

c Déficit fiscal antes de donaciones.

d Después del alivio de la deuda asociado a la Iniciativa para la reducción de la deuda de los países pobres muy endeudados (Iniciativa PPME).

tran una persistencia de los déficit, siendo particularmente notorios los desequilibrios en Honduras y Nicaragua.

Este hecho tiene varias consecuencias indeseables. En primer lugar, dificulta el logro de la estabilidad macroeconómica. Aunque la mayoría de los países ya no financian su déficit con la colocación de papeles en el banco central respectivo, el déficit genera presiones de demanda que obligan a los bancos 
centrales a mantener políticas monetarias austeras, las que elevan las tasas de interés para el sector privado y atraen capitales extranjeros de corto plazo, apreciando las monedas nacionales. Segundo, para evitar que la deuda pública se vuelva insostenible, los países están constantemente sometidos a presiones para que recorten gastos (generalmente de inversión social o en infraestructura física) o para que aumenten las alícuotas de algunos impuestos de fácil recaudación. Por último, la persistencia de los déficit impide que las autoridades económicas utilicen la política fiscal en forma anticíclica. Es claro que los persistentes déficit fiscales hacen que la deuda pública sea insostenible en todos los países de la región y que, por lo tanto, los déficit requieran corrección, ya sea mediante un aumento de la carga tributaria o una disminución de los niveles de gasto. ${ }^{6}$

\section{Implicancias tributarias del Tratado de Libre Comercio (TLC) entre Centroamérica y Estados Unidos}

Entre fines de 2003 y comienzos de 2004 los países miembros del MCCA culminaron la negociación de dicho tratado. Una vez ratificado, éste tendrá connotaciones importantes para las economías centroamericanas. ${ }^{7}$ Sus efectos también se harán sentir en las políticas tributarias de estas economías, dada la magnitud de sus importaciones desde los Estados Unidos, que en 2004 representaron un tercio de las importaciones totales de los países centroamericanos (excluidos los insumos para la maquila, que ya ingresan liberados de derechos de aduana). La recaudación proveniente de los impuestos sobre las importaciones se ubicó entre $0,9 \%$ y $2 \%$ del PIB en ese mismo año.

Basándose en los cronogramas de desgravación ofrecidos por los países en el marco del TLC entre Centroamérica y Estados Unidos, así como en las importaciones provenientes de Estados Unidos y en las tasas arancelarias vigentes, Barreix, Roca y Villela (2004) realizaron un cálculo de las pérdidas recaudatorias asociadas a dicho tratado. En el corto plazo, éstas representarían en promedio 0,4\% del PIB. En el mediano plazo, a medida que las importaciones desde Estados Unidos se vayan desgravando en forma más comple-

\footnotetext{
${ }^{6}$ Véase en Edwards y Vergara (2002) y Vergara (2003) un análisis de la sostenibilidad de la deuda pública en Centroamérica.

7 Véase Agosin y Rodríguez (2005), Todd, Winters y Arias (2004)

y Hathaway (2003).
}

ta, las pérdidas recaudatorias ascenderían a $0,7 \%$ del PIB. Serían menores en El Salvador, Guatemala y Nicaragua $(0,4 \%$ del PIB), y más significativas en Honduras (1,1\% del PIB). En Costa Rica se ubicarían en un nivel intermedio (0,6\% del PIB) ${ }^{8}$ En consecuencia, la reforma tributaria también deberá compensar las pérdidas recaudatorias asociadas al TLC.

\section{Desafíos de la nueva inserción internacional}

La aplicación del modelo de "regionalismo abierto" adoptado por los países de la región a fines del decenio de 1980 se intensificará en los próximos años, lo que planteará desafíos importantes a la política tributaria. Entre ellos se destacan la necesidad cada vez mayor de armonizar los sistemas tributarios de los países integrantes del MCCA a medida que se acrecientan las relaciones económicas y financieras entre ellos, y la exigencia de la omc de que los países de la región desmantelen las exoneraciones del impuesto sobre la renta para empresas ubicadas en zonas francas.

\section{a) Armonización tributaria en el MCCA}

La intensificación de la integración regional supone un esfuerzo por armonizar las políticas tributarias que aún no ha tenido lugar a nivel centroamericano. Por ejemplo, para eliminar las barreras aduaneras al interior de la subregión y facilitar el tránsito de mercaderías dentro de ella es esencial que se armonicen los criterios para determinar el impuesto al valor agregado (IVA) y los impuestos selectivos sobre el consumo. Asimismo, es importante convenir la definición de normas administrativas conjuntas que sustituyan a los controles antes aplicados por las aduanas, con el fin de evitar fraudes fiscales. A pesar de que las tasas del IVA han ido convergiendo, no ha ocurrido lo mismo con los impuestos selectivos sobre el consumo.

Con respecto al impuesto sobre la renta de las sociedades, la necesidad de coordinación es aún mayor para evitar pérdidas de ingresos tributarios en aquellas jurisdicciones que tengan las tasas más altas. En una subregión cada vez más integrada, los

\footnotetext{
${ }^{8}$ Estos cálculos incluyen sólo los efectos directos del desmantelamiento gradual de aranceles. Existen otros efectos que tenderían a agravar las consecuencias adversas sobre la recaudación, como el aumento de las importaciones desde Estados Unidos en desmedro de las provenientes de terceros países. Pero también podrían darse efectos positivos: por ejemplo, el TLC de Centroamérica y Estados Unidos seguramente atraerá inversiones que generarán producción y consumo afectos a impuestos.
} 
grupos económicos con filiales en distintos países tenderán a declarar sus ganancias en los países con tasas más bajas. La solución más sencilla es que las tasas no diverjan mucho entre países. ${ }^{9}$ La más compleja es la adopción de un sistema de precios de transferencia (y normas de capitalización débil) para evitar que las empresas saquen sus utilidades de un país a través de transacciones -o préstamos concertados- entre filiales, especialmente cuando participan en este proceso empresas radicadas en paraísos fiscales. Además, los países centroamericanos deben considerar la firma de acuerdos para evitar la doble tributación con los países originarios de las empresas extranjeras, para reforzar la seguridad jurídica de los inversionistas sobre bases comunes con el fin de mejorar su capacidad negociadora y evitar la competencia nociva y el mal uso de los incentivos.

\section{b) Modelo de promoción de exportaciones y normas de la $\mathrm{OMC}$ \\ La reforma del sistema tributario de los países de} la subregión también está motivada por la necesidad de replantear la estrategia de captación de inversión extranjera directa (IED) y de promoción de exportaciones seguida por los países centroamericanos en la década de 1990. Esa estrategia se basó principalmente en el otorgamiento de beneficios tributarios a las empresas instaladas en zonas francas, siendo la exoneración del pago de impuesto sobre la renta uno de los principales beneficios otorgados.
Actualmente, los crecientes compromisos comerciales internacionales exigen que se dé un tratamiento tributario homogéneo a las empresas nacionales y a las instaladas en zonas francas y, especialmente, que se coordine el tratamiento del impuesto sobre la renta de estas empresas entre los países centroamericanos. De esta forma se evitaría incurrir en una competencia depredadora entre los países por la captación de IED, que tendría graves consecuencias sobre la capacidad de recaudación y la equidad de las estructuras tributarias.

El Acta Final de la Ronda Uruguay de negociaciones comerciales multilaterales, que finalizó en 1995, contiene el Acuerdo SMC mencionado más atrás; a partir del 2003 este debía ser cumplido por los países en desarrollo, excepto aquellos con un ingreso anual per cápita inferior a 1.000 dólares (Honduras y Nicaragua en la subregión centroamericana). Dicho acuerdo prohíbe expresamente la exoneración del impuesto sobre la renta de las sociedades para empresas exportadoras. Sin embargo, en virtud de su artículo 27, el plazo fue extendido por cinco años más en la Cuarta Conferencia Ministerial de la OMC que tuvo lugar en Doha en noviembre del 2001. Mientras se redactaba el presente artículo, el plazo final fue ampliado nuevamente hasta el $1^{\circ}$ de enero del 2010. Con las revisiones de las cuentas nacionales de Honduras (aún incompletas) y de Nicaragua, estos dos países debiesen estar ya cerca del límite de los 1.000 dólares per cápita y ciertamente lo sobrepasarán a comienzos de 2010, con lo cual las normas del Acuerdo SMC también se les aplicarán.

\section{II \\ Panorama tributario de los países centroamericanos}

Si se comparan los años 1990 y 2003, se observa que entre ellos el nivel medio de recaudación experimentó un incremento cercano al 40\%. Además, varios países incorporaron instrumentos tributarios modernos en sus estructuras impositivas - como el IVA- y disminuyeron significativamente los derechos de aduana. Al mismo tiempo, han realizado esfuerzos importantes por mejorar las administraciones tributarias.

\footnotetext{
${ }^{9}$ Como se verá más adelante, las tasas del impuesto sobre la renta han ido convergiendo, pero aún subsisten diferencias importantes.
}

No obstante, aún persiste un esfuerzo tributario insuficiente que ubica a estos países por debajo de su capacidad recaudatoria. Además, sus sistemas tienden a ser regresivos debido a una débil tributación sobre la renta, y son muy centralizados, por lo que los impuestos sobre la propiedad no son importantes. Después de las reformas efectuadas en la década de 1990, que podrían definirse como "de primera generación", la región requiere nuevos compromisos de reforma que modernicen los sistemas tributarios y los hagan aptos para enfrentar los desafíos que se describen en la primera parte de este artículo. 


\section{Situación actual de la política tributaria}

\section{a) Evolución del nivel de los ingresos tributarios totales}

Como muestra el cuadro 2, el nivel medio de la carga tributaria ha tenido una tendencia ascendente que exhibe una marcada variabilidad. Esta se debe esencialmente a las limitaciones impuestas a las bases imponibles de los tributos por el amplio número de exenciones y desgravaciones, así como por los niveles de incumplimiento y evasión que existen en Centroamérica, los cuales han llevado a la necesidad de efectuar reformas tributarias periódicas para recuperar los niveles de presión impositiva.

Pese a la evolución del nivel tributario medio de la subregión, varios países tienen todavía una carga impositiva muy baja. Además, la continua liberalización del comercio exterior en estos países ha impuesto una pesada tarea a las administraciones tributarias; ellas han tenido que asumir la responsabilidad de recuperar los ingresos que antes obtenían más fácilmente a través de las aduanas, y ahora deben administrar un sistema más complejo y controlar a un mayor número de contribuyentes internos.

Como ya se ha señalado, los países centroamericanos han buscado resarcirse de las pérdidas de ingresos tributarios debidas a la liberalización del comercio exterior, recurriendo a aumentos sucesivos del IVA. Varios países han tratado de contrarrestar lo que perciben como un efecto regresivo de este impuesto, otorgando exenciones sustanciales y tratamientos técnicos

CUADRO 2

\section{Países centroamericanos: Carga tributaria, 1990-2003a}

(Porcentaje del PIB)

\begin{tabular}{lrrrr}
\hline & 1990 & 1995 & 2000 & 2003 \\
\hline Costa Rica & 10,8 & 11,4 & 11,9 & 13,0 \\
El Salvador & 7,6 & 11,9 & 11,0 & 12,6 \\
Guatemala & 6,9 & 8,0 & 9,5 & 10,3 \\
Honduras & 15,0 & 17,3 & 16,6 & 15,9 \\
Nicaragua & 8,1 & 12,2 & 14,5 & 15,8 \\
Centroamérica & & & & \\
(promedio simple) & 9,7 & 12,2 & 12,7 & 13,5 \\
\hline
\end{tabular}

Fuente: Agosin, Barreix y Machado (2005).

a Los datos no incluyen los ingresos correspondientes a la seguridad social. El PIB de Honduras no ha sido corregido por su subestimación. Las cifras para Nicaragua utilizan las nuevas estimaciones del PIB del Banco Central de Nicaragua realizadas en 2003. En Honduras no hay datos oficiales que corrijan la subestimación. En todos los cuadros de aquí en adelante se utilizan las cifras oficiales de los países. poco convenientes a los bienes incluidos en la canasta de consumo (tasa cero en el IVA). La tasa cero otorga el derecho a que los productores de un bien que se benefician de ella recuperen los créditos generados por pagos de IVA sobre los insumos. Esto se presta para abusos y reduce la productividad del tributo, afectando adversamente el nivel de la carga impositiva.

\section{b) Evolución de la estructura tributaria}

Entre 1990 y 2002, se observan patrones muy definidos en la estructura tributaria de los países de la subregión. Ya se mencionó el reemplazo de los gravámenes sobre las importaciones por el IVA. El segundo cambio significativo fue la reducción de las tasas legales máximas del impuesto sobre la renta tanto de las personas como de las empresas, desde niveles superiores a $40 \%$ hasta niveles inferiores a $30 \%$.

Tercero, a lo largo del período la participación de los impuestos directos en relación con la de los indirectos se mantuvo constante. Mientras que los impuestos directos generaron el $24 \%$ del total de los ingresos tributarios en el promedio de los trece años considerados, los impuestos indirectos aportaron el 76\% restante; cabe señalar, sin embargo, que durante el último quinquenio se observó una leve tendencia creciente hacia una mayor participación de los impuestos directos. Este comportamiento se explica por la incorporación de nuevos contribuyentes en la base de los impuestos sobre la renta, a pesar de la reducción de las tasas, y por la disminución de la importancia de ciertos impuestos indirectos (selectivos y sobre el comercio exterior).

Cuarto, fue alta la gravitación del IVA recaudado en el ámbito de las aduanas (es decir, en el momento en que los bienes son importados), que representó más del $50 \%$ de la recaudación total de este impuesto. La importancia del gravamen recaudado en las aduanas ha contribuido a reducir la tasa media de evasión del tributo, ya que la administración tributaria debe ocuparse de recaudar solamente el gravamen generado en las fuentes internas.

Por último, los impuestos de tipo selectivo, aunque erráticos de un año a otro, aportaron aproximadamente el $15 \%$ del total recaudado. Fue clara la tendencia hacia una mayor participación de los impuestos sobre los combustibles, y al mismo tiempo hacia una disminución de la cantidad de bienes gravados, que fueron principalmente productos como tabaco y bebidas.

En síntesis, y debido a estos cambios, se observa que fueron los impuestos indirectos los que más pesaron en la evolución de la carga tributaria en la última 
década. La participación en el monto recaudado de los tributos de tipo directo, bajo la forma de impuestos sobre la renta o sobre el patrimonio, no tuvo cambios significativos durante el período.

Como puede apreciarse en el cuadro 3 , que muestra la estructura de la recaudación en el 2002, son los impuestos indirectos los que siguen generando el grueso de la recaudación. Ello estaría indicando que las reformas deberían centrarse en la imposición directa, la cual apenas recauda alrededor del 3\% del PIB.

\section{c) Los estímulos a la inversión extranjera y los tra- tamientos preferenciales}

La transición desde un modelo de desarrollo basado en la sustitución de importaciones a otro de economía abierta estuvo acompañada de una serie de medidas de estímulo - muchas de ellas con alto contenido tributario- que también tuvieron impacto en la recaudación de otros tributos. La expansión de las exportaciones se concentró fuertemente en empresas (tanto extranjeras como nacionales) radicadas en zonas francas y dedicadas fundamentalmente a la confección a partir de insumos provenientes de Estados Unidos (las llamadas maquiladoras). También hubo importantes inversiones en turismo, pesca (especialmente el cultivo de camarones) y minería. Para estimular estas inversiones se otorgaron amplias y generosas exencio- nes de impuestos sobre la renta y el patrimonio, liberando total o parcialmente a la inversión del pago de estos impuestos. Además, se otorgó el mismo tratamiento dado a los inversionistas extranjeros a las empresas nacionales instaladas en zonas francas e, incluso, a las proveedoras de las empresas de esas zonas.

No existe unanimidad entre los analistas sobre cuán importantes han sido estas exoneraciones —que, dicho sea de paso, se han convertido en cuasipermanentes - para atraer inversiones hacia sectores que, después de todo, tienen ventajas comparativas importantes en la subregión. Lo que sí es incontrovertible es que estas medidas mermaron la capacidad de los gobiernos de generar recursos tributarios. Como esas actividades han estado entre las más dinámicas de las economías centroamericanas, la baja elasticidad de la recaudación con respecto al crecimiento del PIB debe atribuirse en buena parte a las exoneraciones que las han favorecido.

Es difícil justificar las exoneraciones para las empresas nacionales ubicadas en zonas francas. Para los inversionistas extranjeros, la importancia de las exoneraciones del impuesto sobre la renta depende de su política de dividendos y de la legislación de su país de origen. Para las empresas estadounidenses, que constituyen la gran mayoría de las empresas extranjeras ubicadas en los países centroamericanos, la

CUADRO 3

Países centroamericanos: Carga tributaria por tipo de impuestos, 2002

(Porcentaje del PIB)

\begin{tabular}{|c|c|c|c|c|c|}
\hline Concepto & Costa Rica & El Salvador & Guatemala & Honduras & Nicaragua \\
\hline Total de ingresos tributarios & 12,8 & 12,0 & 10,6 & 16,1 & 14,3 \\
\hline Ingresos tributarios directos & 3,5 & 3,5 & 2,8 & 3,7 & 2,8 \\
\hline Impuesto sobre la renta & 3,1 & 3,4 & 2,8 & 3,5 & 2,8 \\
\hline Impuesto sobre la propiedad & 0,4 & 0,1 & 0,0 & 0,2 & 0,0 \\
\hline Ingresos tributarios indirectos & 9,3 & 8,5 & 7,8 & 12,3 & 11,4 \\
\hline Generales & 4,9 & 6,3 & 4,8 & 5,5 & 5,9 \\
\hline Internos & .. & 3,0 & 1,9 & .. & .. \\
\hline De importación & .. & 3,3 & 2,9 & .. & .. \\
\hline Específicos & 1,1 & 1,1 & 1,5 & 1,9 & 3,7 \\
\hline Derivados del petróleo & .. & 0,6 & 0,9 & 0,7 & 2,5 \\
\hline Resto & .. & 0,5 & 0,6 & 1,2 & 1,3 \\
\hline $\begin{array}{l}\text { Comercio y transacciones } \\
\text { internacionales }\end{array}$ & 0,9 & 1,1 & 1,2 & 2,0 & 1,1 \\
\hline Otros indirectos & 2,4 & 0,0 & 0,3 & 2,9 & 0,7 \\
\hline
\end{tabular}

Fuente: Agosin, Barreix y Machado (2005). 
situación es la siguiente: si ellas remesan los dividendos inmediatamente después de haber registrado las utilidades, cualquier tasa inferior a $35 \%$ (la tasa de impuesto sobre la renta de las empresas prevaleciente en Estados Unidos) significa simplemente una transferencia de recaudación desde el país receptor de la inversión hacia el Tesoro estadounidense, sin ningún efecto sobre ellas mismas.

Si dichas empresas no remesan a su casa matriz los dividendos en forma inmediata, no tienen que tributar sobre esas utilidades en Estados Unidos hasta que ellas sean efectivamente remesadas, y esto les da una liquidez que no hubiesen tenido de otro modo. Por ende, es probable que las empresas exageren el valor que tienen dichas exoneraciones. El resultado indudable de este proceso es una pérdida de recursos para los fiscos centroamericanos.

Otro tema recurrente en los países de la subregión durante la última década ha sido la proliferación y diversidad de regímenes de incentivos, tanto en las actividades internas como en aquellas directamente vinculadas al comercio exterior. La promoción de actividades relacionadas con el turismo, la construcción, el sector agropecuario y la minería, entre otras, así como el florecimiento de zonas francas y zonas libres de impuestos, son constantes que se repiten en cada uno de los países. Ha habido exoneraciones no sólo del impuesto sobre la renta de las empresas sino también de los derechos de importación de insumos y bienes de capital y de los gravámenes indirectos nacionales. En el cuadro 4 se describen los beneficios tributarios otorgados en zonas francas por los países de Centroamérica.

La falta de información respecto a quiénes son los beneficiarios de estas exenciones e incentivos y cuál es su orden de magnitud ha impedido estimar el total de impuestos que estos países han dejado de percibir por tales conceptos. Estos beneficios, que se denominan técnicamente "gastos tributarios" y que corresponden al conjunto de impuestos y gravámenes que no se generan por estar relacionados con actividades promocionadas, tienen un costo adicional para la administración tributaria, en la medida en que ésta tenga que discernir, dentro del universo de potenciales contribuyentes, quién se está o no se está beneficiando con alguno de los regímenes de incentivos.

CUADRO 4

Países centroamericanos: Incentivos fiscales en zonas francas, 2002

(Porcentajes)

\begin{tabular}{|c|c|c|c|c|c|}
\hline Incentivos & Costa Rica & El Salvador & Guatemala & Honduras & Nicaragua \\
\hline $\begin{array}{l}\text { Exención del impuesto } \\
\text { a la importación }\end{array}$ & 100 & 100 & 100 & 100 & 100 \\
\hline $\begin{array}{l}\text { Exención del impuesto } \\
\text { sobre la renta }\end{array}$ & $\begin{array}{l}100 \% \text { por } 8 \text { años } \\
50 \% \text { por los } \\
\text { siguientes } 4 \text { años }{ }^{\mathrm{a}}\end{array}$ & $100 \%$ por 20 años & $100 \%$ por 12 años & 100 & $\begin{array}{c}100 \% \text { por } 10 \text { años } \\
60 \% \text { después }\end{array}$ \\
\hline $\begin{array}{l}\text { Exoneración de la } \\
\text { repatriación de ganancias }\end{array}$ & 100 & 100 & 100 & 100 & 100 \\
\hline Exención del IVA & 100 & $\begin{array}{c}100 \% \text { por } 10 \text { años } \\
\text { y renovable }\end{array}$ & 100 & 100 & 100 \\
\hline $\begin{array}{l}\text { Exención de impuestos } \\
\text { sobre activos }\end{array}$ & $100 \%$ por 10 años & 100 & 100 & 100 & 100 \\
\hline $\begin{array}{l}\text { Exención a impuestos } \\
\text { y tasas municipales }\end{array}$ & $100 \%$ por 10 años & $100 \%$ por 20 años & 100 & 100 & 100 \\
\hline $\begin{array}{l}\text { Límites a ventas } \\
\text { locales }\end{array}$ & $\begin{array}{c}\text { Hasta } 25 \% \text { en } \\
\text { manufactura } \\
50 \% \text { por servicios }\end{array}$ & Ninguno & $\begin{array}{l}\text { Hasta } 20 \% \text { para } \\
\text { manufacturas }\end{array}$ & $\begin{array}{c}\text { Con aprobación del } \\
\text { Min. de Economía: } \\
\text { Hasta } 5 \% \text { en } \\
\text { manufacturas } \\
\text { Hasta } 50 \% \text { en servicios }\end{array}$ & $\begin{array}{l}\text { Con aprobación del } \\
\text { Min. de Economía: } \\
\text { Entre } 20 \%-40 \% \text {, } \\
\text { dependiendo del } \\
\text { tipo de firma }\end{array}$ \\
\hline
\end{tabular}

Fuente: Rodríguez y Robles (2003).

a Los plazos se extienden a 12 y 6 años en zonas de menor desarrollo. 
Desde luego, las exoneraciones han debido ser compensadas con una mayor carga tributaria sobre los sectores no promovidos, lo que altera las condiciones de equidad horizontal al imponer cargas tributarias disímiles sobre agentes económicos que están en igualdad de condiciones.

La amplitud que han adquirido estos beneficios desde la década de 1990 y la ausencia de datos detallados sobre los diversos sistemas hacen muy difícil efectuar una comparación entre los países de la subregión respecto a los sectores beneficiados, el tipo y profundidad de los beneficios y los resultados que se han obtenido con cada uno de ellos.

\section{Principales características de los impuestos vigentes}

\section{a) El impuesto sobre la renta}

Pese a los avances registrados en la modernización de otros impuestos, el impuesto sobre la renta (IR) en los países centroamericanos sigue adoleciendo de antiguos problemas. De manera general, el impuesto sobre la renta personal (IRP) tiene carácter cedular (en contraposición a global). Esto significa que cada tipo de ingreso está vinculado a un régimen impositivo distinto con tasas diferentes. Además, existe un gran número de exenciones según la fuente generadora (seguros, intereses, dividendos y otras rentas financieras y de capital). Esto determina que, en la práctica, casi la totalidad de la tributación recaiga sobre los salarios de los trabajadores en relación de dependencia, lo que atenta contra la equidad horizontal y vertical y mina la eficacia recaudatoria. Si a esto se agregan las altas proporciones de trabajadores informales y por cuenta propia que se observan en los países centroamericanos, es fácil entender la escasa recaudación que genera el impuesto considerado.

Por otra parte, el IRP se basa en el concepto de renta territorial, de modo que no grava las rentas generadas en el exterior. Aunque es difícil identificar tales rentas, la adopción del principio de renta mundial sería una forma de cerrar vías potencialmente importantes de evasión y permitiría otorgar más instrumentos de fiscalización a la autoridad tributaria.

Como ya se ha señalado, el impuesto sobre la renta de las sociedades (IRS) también presenta un conjunto de exoneraciones subjetivas, fundamentalmente para las empresas extranjeras instaladas en zonas francas, y para sectores protegidos y/o promovidos, como la agricultura y el turismo. En cuanto a la modernización del diseño de este impuesto, en términos generales puede decirse que la legislación de los países centroamericanos no ha incorporado normas sobre precios de transferencia, capitalización débil, transferencia de utilidades desde y hacia paraísos fiscales, y otros mecanismos comúnmente utilizados por las empresas transnacionales para reducir su carga tributaria mediante el traslado de sus utilidades de un país a otro.

En el cuadro 5 se observa que la recaudación del IR en los países centroamericanos en 2002 ascendió a $3,1 \%$ del PIB (24,2\% de la recaudación), inferior en 0,7 puntos porcentuales a la de los países latinoamericanos. La procedencia de estos ingresos varía mucho de un país a otro: en promedio, 38,9\% proviene de las empresas, participación inferior en más de 11 puntos porcentuales al promedio de América Latina. En El Salvador, las personas jurídicas aportan un porcentaje elevado del IR $(61,7 \%)$, mientras que en Honduras éstas aportan apenas el 18,2\%.

Si bien ha habido una caída generalizada de las tasas del IRS en las décadas más recientes, lo que ha reducido la productividad en los países centroamericanos ha sido la erosión de la base tributaria. En promedio, esa productividad ha sido de $6,7 \%$. Esto indica que cada punto porcentual de tasa de IRS recauda 0,067 puntos porcentuales del PIB. Sorprendentemente, la menor productividad de este impuesto se observa en Costa Rica (3,5\%), mientras que en Honduras la cifra es mayor $(8,6 \%)$. Sin embargo, esta última parecería estar sobreestimada, dada la significativa subestimación del PIB hondureño.

En lo que se refiere al IRP, como es usual, los países centroamericanos tienen un tramo mínimo exento. El tramo exento equivale a 3,1 veces el PIB per cápita. Guatemala y Nicaragua registran los mayores niveles de exención, que más que duplican el promedio latinoamericano. Si bien estas exoneraciones introducen un efecto progresivo en la estructura tributaria, pueden desvirtuarse si se fijan a niveles muy elevados, además de erosionar la base del tributo.

El tramo máximo del IRP alcanza a 22,1 veces el PIB per cápita en los países centroamericanos, cifra ligeramente por encima del promedio de América Latina; pero parecería ser muy alto en Honduras y Nicaragua, donde se ubica respectivamente en 36 y 37,5 veces el PIB por habitante. Nuevamente, en el caso de Honduras la cifra tendría un claro sesgo hacia arriba debido a la subestimación del PIB.

En síntesis, pese a la racionalización de las tasas del IRP y del IRS, en todos los países se observa que la renta neta gravable declarada es significativamente inferior a la renta bruta. Esto pone en evidencia la apreciable erosión de la base tributaria, lo que está asociado principalmente a las excesivas exoneraciones 
Países centroamericanos: Impuesto sobre la renta, ${ }^{a} 2002$

\begin{tabular}{|c|c|c|c|c|c|c|c|c|}
\hline & $\begin{array}{c}\text { Tasas del IRS } \\
(\%)\end{array}$ & $\begin{array}{c}\text { Tasas del IRP } \\
(\%)\end{array}$ & $\begin{array}{c}\text { Recaudación } \\
\text { del IRS } \\
\text { (\% de la recau- } \\
\text { dación del IR) }\end{array}$ & $\begin{array}{l}\text { Productividad } \\
\text { del IRS } \\
(\%)\end{array}$ & $\begin{array}{l}\text { Mínimo } \\
\text { exento } \\
\text { del IRP }\end{array}$ & $\begin{array}{l}\text { Tramo } \\
\text { máximo } \\
\text { del IRP }\end{array}$ & $\begin{array}{l}\text { Participación } \\
\text { del IR en la } \\
\text { recaudación } \\
\text { tributaria total } \\
\quad(\%)\end{array}$ & $\begin{array}{c}\text { Recaudación } \\
\text { del IR } \\
\text { (\% del PIB) }\end{array}$ \\
\hline Costa Rica & 30,0 & $10-25$ & 20,8 & 3,5 & 0,8 & 3,7 & 23,9 & 3,1 \\
\hline El Salvador & 25,0 & $10-30$ & 61,7 & 7,8 & 1,2 & 11,0 & 28,3 & 3,4 \\
\hline Guatemala $^{\mathrm{d}}$ & 31,0 & $15-31$ & 55,0 & 3,7 & 5,0 & 22,5 & 26,4 & 2,8 \\
\hline Honduras & 15 y 25 & $10-25$ & 18,2 & 8,6 & 3,6 & 36,0 & 22,0 & 3,5 \\
\hline Nicaragua $^{\mathrm{e}}$ & 25,0 & $10-25$ & .. &.. & 4,7 & 37,5 & 19,8 & 2,8 \\
\hline Promedio & 27,2 & $11-27,2$ & 38,9 & 6,7 & 3,1 & 22,1 & 24,2 & 3,1 \\
\hline América Latina ${ }^{\mathrm{f}}$ & 28,3 & $8,7-27,7$ & 50,0 & 6,2 & 2,1 & 20,7 & 27,7 & 3,8 \\
\hline
\end{tabular}

Fuente: Agosin, Barreix y Machado (2005); Stotsky y WoldeMariam (2002); Barreix, Roca y Villela (2004).

a IR: impuesto sobre la renta; IRS: impuesto sobre la renta de las sociedades; IRP: impuesto sobre la renta de las personas.

b Recaudación del IRS como porcentaje del PIB dividido por la tasa máxima del IRS.

c Múltiplos del PIB per cápita.

d Incluye el impuesto sobre las empresas mercantiles y agrícolas (IEMA).

e En mayo del 2003 la tasa máxima fue elevada a 30\% tanto para personas naturales como para personas jurídicas.

f Incluye 17 países. Las cifras corresponden al promedio 2000-2001.

objetivas y subjetivas que, además de atentar contra la equidad horizontal y vertical del sistema tributario, producen pérdidas significativas de recaudación.

\section{b) El impuesto sobre los activos}

En algunos países existe un impuesto mínimo sobre la renta de las personas jurídicas. Este impuesto presume una rentabilidad mínima de los activos de una empresa y se aplica sobre el valor fiscal de ellos o, en algunos casos, sobre las ventas. En países donde las normas contables son poco claras o fáciles de interpretar a favor de los intereses de las empresas, este gravamen es más difícil de eludir que el impuesto sobre las ganancias netas. El impuesto sobre los activos es un pago mínimo a cuenta del IRS y opera como una retención que se deduce de la obligación tributaria sobre las ganancias. En aquellos casos en que la empresa declara menos impuestos que lo pagado a cuenta, el impuesto sobre los activos se vuelve pago definitivo.

Como puede apreciarse en el cuadro 6, la mayoría de los países ha utilizado, o todavía está utilizando, este tipo de impuestos. Después de su implementación, estos tributos comenzaron a tener un efecto cada vez menor debido al aumento del monto mínimo de capital requerido para aplicarlos y a la paulatina disminución de las tasas. En algunos casos fueron derogados, cediendo así a la fuerte oposición que enfrentaron en todos los países. Sin embargo, cuando las tasas son moderadas (con un máximo de 1,5\%), estos tributos resultan deseables, pues contribuyen a mejorar el nivel de captación del IRS ante la ausencia de normas contables fidedignas y la debilidad de las administraciones tributarias. También se debe reconocer que las imprecisiones en su diseño han generado problemas de doble tributación para las filiales de empresas transnacionales, ya que algunos países desarrollados no otorgan crédito fiscal por pagos a cuenta de este impuesto.

\section{c) El impuesto sobre el valor agregado (IVA)}

El IVA se introdujo en la mayoría de los países centroamericanos durante los decenios de 1970 y 1980 , pero el vertiginoso incremento de su participación en las recaudaciones es un fenómeno que se observa a partir de la década de 1990. Este proceso se explica fundamentalmente por el aumento de sus tasas y en menor grado por su extensión a los servicios. Si se compara la alícuota general del IVA en el año de introducción del impuesto con la vigente en el 2002, se aprecia que esta se elevó entre 3 y 9 puntos porcentuales. Así, la tasa general media en la región subió de $7 \%$ a $13 \%$.

En general, el diseño del IVA en los países centroamericanos adolece de dos problemas fundamentales que erosionan la base de este tributo, introducen distorsiones en la economía, atentan contra la equidad y dificultan la administración: ellos son las excesivas exenciones y el uso de la tasa cero. 
Los bienes y servicios más comúnmente exentos del IVA en los países centroamericanos son los productos de la canasta básica de consumo y el transporte, los servicios médicos y educativos, las transacciones financieras y de seguros, y la energía y combustibles. Al igual que en el caso del IR, además de estas exoneraciones objetivas existen también exoneraciones subjetivas para diversos contribuyentes - como organizaciones no gubernamentales (ONG), municipalidades, instituciones sin fines de lucro-y para el sector agrícola y las empresas establecidas en zonas francas.

Estas distorsiones se agravan por la aplicación de la tasa cero a bienes destinados al mercado interno. $\mathrm{Si}$ bien esta práctica es adecuada en el caso de los exportaciones a fin de no restarle competitividad a los pro- ductores locales, en el caso de los bienes destinados al consumo interno no solo erosiona la base del tributo sino que también abre una importante vía de evasión (e incluso de corrupción).

Como ya se mencionó, el IVA se ha convertido en la principal fuente de recaudación de los países centroamericanos. En el 2002 representó 43\% de la recaudación tributaria total y su contribución como porcentaje del PIB estuvo entre 4,8 y 6,3\%. Sin embargo, la recaudación media (5,3\% del PIB) es inferior al promedio latinoamericano en 0,8 puntos porcentuales del PIB (cuadro 7).

La reducida productividad del impuesto, que solo alcanza a 40,8\%, evidencia los elevados niveles de evasión y las excesivas exoneraciones y uso de la tasa

CUADRO 6

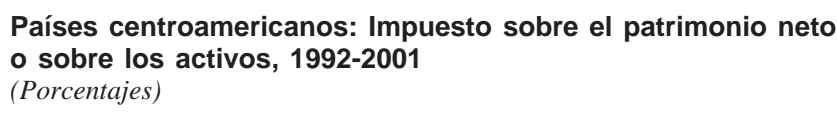

\begin{tabular}{|c|c|c|c|c|c|}
\hline Año & Costa Rica & El Salvador & Guatemala & Honduras & Nicaragua \\
\hline 1992 & $\begin{array}{c}0,36-1,17 \text { sobre los } \\
\text { activos fijos }\end{array}$ & $\begin{array}{c}0,9-2,0 \text { sobre los } \\
\text { activos }\end{array}$ & $\begin{array}{l}\text { 0,3-0,9 sobre los } \\
\text { inmuebles }^{\mathrm{a}}\end{array}$ & $\ldots$ & $\begin{array}{l}1,5-2,5 \text { sobre el } \\
\text { patrimonio neto }\end{array}$ \\
\hline \multirow[t]{2}{*}{2001} & 1,0 sobre los activos & $\ldots$ & $\begin{array}{l}\text { 0,2-0,9 sobre los } \\
\text { inmuebles }\end{array}$ & $\begin{array}{c}0,25 \text { sobre los } \\
\text { activos }^{b}\end{array}$ & $\begin{array}{l}1,0 \text { sobre los } \\
\text { inmuebles }\end{array}$ \\
\hline & & & 3,5 sobre los activos ${ }^{c}$ & & \\
\hline
\end{tabular}

Fuente: Stotsky y WoldeMariam (2002).

a La base está formada por los bienes inmuebles pero el impuesto está concebido como un tributo adicional sobre las empresas.

b Grava los activos fijos mayores a 750.000 lempiras que posean las compañías al final del período impositivo.

c Impuesto de 3,5\% de los activos o 2,25\% de los ingresos brutos declarados en la declaración jurada del impuesto a las ganancias del año anterior.

CUADRO 7

Países centroamericanos: Impuesto al valor agregado, 2002

(Porcentajes)

\begin{tabular}{|c|c|c|c|c|c|}
\hline & Tasa general & Tasa especial & Productividad $^{\mathrm{a}}$ & $\begin{array}{l}\text { Participación del } \\
\text { IVA en la recaudación } \\
\text { tributaria total }\end{array}$ & $\begin{array}{l}\text { Recaudación del } \\
\text { IVA (\% del PIB) }\end{array}$ \\
\hline Costa Rica & 13,0 & & 37,7 & 38,3 & 4,9 \\
\hline El Salvador & 13,0 & & 48,5 & 52,5 & 6,3 \\
\hline Guatemala & 12,0 & & 40,0 & 45,3 & 4,8 \\
\hline Honduras & 12,0 & 15 & 45,8 & 34,3 & 5,5 \\
\hline Nicaragua & 15,0 & 5 y 6 & 39,3 & 41,2 & 5,9 \\
\hline Promedio & 13,0 & & 40,8 & 43,0 & 5,3 \\
\hline América Latina ${ }^{\mathrm{b}}$ & 14,5 & & 42,1 & 44,2 & 6,1 \\
\hline
\end{tabular}

Fuente: Agosin, Barreix y Machado (2005); Barreix, Roca y Villela (2004).

a Recaudación del IVA como porcentaje del PIB dividido por la tasa general.

b Incluye 17 países. Las cifras corresponden al promedio 2000-2001. 
cero. Los países cuyo IVA exhibe la más baja productividad son Costa Rica y Nicaragua (37,7\% y 39,3\%, respectivamente), lo que se debe a las múltiples perforaciones del tributo en estos dos países. Adicionalmente, en Costa Rica este impuesto no grava a los servicios. En contraste, El Salvador y Honduras muestran productividades superiores al $45 \%$. En este último país, sin embargo, los cálculos estarían sesgados al alza, por la ya mencionada subestimación del PIB.

La literatura económica sugiere que el diseño óptimo del IVA es el que establece el uso de una tasa única, aplicable a la base más amplia posible. ${ }^{10}$ Este enfoque prioriza la neutralidad entre sectores y la simplicidad administrativa, reduciendo las oportunidades de evasión. Asimismo, la generalización del IVA mantiene la producción interna en igualdad de condiciones respecto de las importaciones. En efecto, en un mercado integrado con arancel cero, como lo sería con el TLC entre Centroamérica y Estados Unidos, el comercio intrarrama perjudica al productor nacional si está excluido del iva. Esto se debe a que el bien importado entra al país sin la carga del iva que le fuera devuelto por el fisco de su país, en tanto que el productor nacional no puede descontar el IVA de los insumos comprados (porque está excluido el producto final). El perjuicio será tanto mayor mientras menos integrado verticalmente sea el proceso de producción del bien o servicio en cuestión. De estar gravados prácticamente todos los bienes y servicios, el productor nacional tendrá la posibilidad de descontar el IVA de sus insumos y el importador pagará iva a la misma tasa, poniéndolos en igualdad de condiciones para competir (Arias, Barreix y otros, 2005).

De todas maneras, es reconocido que, en economías donde todos los bienes están sujetos al pago de IVA, el impacto de este impuesto en la distribución del ingreso es regresivo. Aunque algunos estudios recientes cuestionan esta hipótesis, ${ }^{11}$ lo que no puede dudarse

\footnotetext{
10 Véase, por ejemplo, Engel, Galetovic y Raddatz (1999).

11 Véase Houghton (2004) y Jenkins y Kuo (2004). El argumento es que, en países de menor desarrollo, el sector informal es muy extendido y los productos que se transan en el mercado informal no son alcanzados por el IVA. Al mismo tiempo, los segmentos más pobres de la población hacen un elevado porcentaje de sus compras en ese mercado (o producen para el autoconsumo), mientras que los más pudientes compran en establecimientos formales que sí deben pagar el IVA. Así, mientras la totalidad del consumo de los sectores de mayores ingresos queda sujeta al IVA, una parte importante del consumo de los sectores de menores ingresos no es alcanzada por este tributo.
}

es que las exenciones del IVA o los tratamientos de tasa cero para bienes que tienen una fuerte incidencia sobre la canasta familiar de los más pobres (alimentos) no es la manera más eficaz de lograr una mayor equidad. Como los más pudientes son los que consumen la mayor proporción de los bienes favorecidos, las exoneraciones y tratamientos de tasa cero erosionan fuertemente la base tributaria y disminuyen la capacidad del Estado para aplicar políticas redistributivas por la vía del gasto. Más efectivo es recaudar a través de un IVA parejo y subsidiar el consumo de los pobres.

En síntesis, a pesar de que en los últimos años se ha observado tanto un aumento de la importancia recaudatoria del IVA como una convergencia en las tasas generales hacia niveles cada vez más adecuados y similares (lo que facilita el proceso de integración comercial), aún persisten serios problemas asociados a las excesivas exoneraciones y al uso de la tasa cero para los no exportadores, que erosionan significativamente la base tributaria y reducen la productividad del impuesto. El uso de la tasa cero para no exportadores constituye además un formidable mecanismo de evasión y genera considerables costos administrativos.

\section{d) Los impuestos selectivos al consumo (ISC)}

Durante los últimos años los países centroamericanos han logrado avances importantes en tres aspectos: los niveles de los ISC, la reducción del número de bienes y servicios gravados y la mayor aplicación de tasas ad valorem en lugar de tasas específicas. Como se observa en el cuadro 8 , el ISC aportó 1,5\% del PIB en el 2002 (12,2\% de la recaudación total), nivel inferior en 0,6 puntos porcentuales al promedio de los países latinoamericanos. Nicaragua es el país donde estos impuestos recaudan más, con 3,7\% del PIB (equivalente al $26,8 \%$ de los ingresos tributarios). En el resto de los países, el ISC recauda entre $1 \%$ y $2 \%$ del PIB (oscilando entre $8 \%$ y $14 \%$ de la recaudación tributaria).

En algunos casos el bajo nivel de las tasas sugiere que habría espacio para alzarlas, como en el caso de los cigarrillos y las bebidas gaseosas en Honduras. El Salvador tiene tasas sistemáticamente reducidas, lo cual explica la baja recaudación del ISC. ${ }^{12}$ En Guatemala, por su parte, el IsC toma la forma de tasas específicas, lo que resta elasticidad a la estructura tributaria por no incorporar las variaciones en el precio de los bienes y servicios gravados. En

\footnotetext{
12 A inicios del 2005 las tasas del ISC sobre los cigarrillos y las
} bebidas alcohólicas fueron elevadas significativamente. 
Países centroamericanos: Impuestos selectivos al consumo, 2002

(Porcentajes)

\begin{tabular}{|c|c|c|c|c|c|c|c|}
\hline & \multicolumn{7}{|c|}{ Tasas $^{\text {a }}$} \\
\hline & Cigarrillos & Cervezas & Ron & $\begin{array}{l}\text { Bebidas } \\
\text { gaseosas }\end{array}$ & $\begin{array}{c}\text { Gasolina } \\
\text { superior }\end{array}$ & $\begin{array}{l}\text { Participación } \\
\text { en la recaudación } \\
\text { tributaria total }\end{array}$ & $\begin{array}{l}\text { Recaudación } \\
\text { (\% del PIB) }\end{array}$ \\
\hline Costa Rica & 70,0 & 45,0 & 60,0 & 30,0 & Específico & 8,4 & 1,1 \\
\hline El Salvador & 39,0 & $20,0^{\mathrm{b}}$ & $20,0^{\mathrm{a}}$ & 10,0 & Específico & 9,2 & 1,1 \\
\hline Guatemala & 100,0 & Específico & Específico & Específico & Específico & 14,2 & 1,5 \\
\hline Honduras & 32,0 & 33,0 & $158,0^{\mathrm{c}}$ & 8,0 & Específico & 11,8 & 1,9 \\
\hline Nicaragua & 40,0 & 37,0 & $37,0^{\mathrm{d}}$ & 14,5 & Específico & 26,8 & 3,7 \\
\hline Centroamérica & & & & & & 12,2 & 1,5 \\
\hline América Latina ${ }^{\mathrm{e}}$ & & & & & & 15,4 & 2,1 \\
\hline
\end{tabular}

Fuente: Agosin, Barreix y Machado (2005); Barreix, Roca y Villela (2004).

a Debido a la variación frecuente que tienen las tasas de los impuestos selectivos al consumo (ISC), los niveles indicados en el cuadro pueden diferir de los que existen actualmente.

b Al $20 \%$ ad valorem debe sumarse 0,0057 dólares por cada $1 \%$ de volumen de alcohol/litro.

c Para el resto de las bebidas alcohólicas es de 445 más un 20\% adicional.

d Para el resto de las bebidas alcohólicas es de $37 \%$.

e Incluye 17 países. Las cifras corresponden al promedio 2000-2001.

CUADRO 9

Países centroamericanos: Impuestos sobre el comercio exterior, 2002 (Porcentajes)

\begin{tabular}{lcccc}
\hline & $\begin{array}{c}\text { Arancel promedio } \\
\text { ad valorem }\end{array}$ & $\begin{array}{c}\text { Desviación } \\
\text { estándar }\end{array}$ & $\begin{array}{c}\text { Participación de estos } \\
\text { impuestos en la recaudación } \\
\text { tributaria total }\end{array}$ & $\begin{array}{c}\text { Recaudación de estos } \\
\text { impuestos como } \\
\% \text { del PIB }\end{array}$ \\
\hline Costa Rica & 6,0 & $\ldots$ & 7,3 & 0,9 \\
El Salvador & 5,6 & 8,6 & 9,2 & 1,1 \\
Guatemala & 5,9 & 8,0 & 11,3 & 1,2 \\
Honduras & 5,3 & $\ldots$, & 12,5 & 2,0 \\
Nicaragua & 5,2 & 5,8 & 7,9 & 1,1 \\
Promedio & 5,6 & 7,5 & 9,5 & 1,2 \\
América Latina & 10,1 & 6,9 & 8,9 & 1,2 \\
\hline
\end{tabular}

Fuente: Agosin, Barreix y Machado (2005); Barreix, Roca y Villela (2004).

a Incluye 17 países. Las cifras corresponden al promedio 2000-2001.

vista de la baja elasticidad-precio de la demanda por estos bienes, un aumento de las tasas no reduciría las cantidades transadas de manera significativa, con lo que subiría la recaudación tributaria.

\section{e) Los impuestos sobre el comercio exterior}

Como consecuencia de la liberalización comercial del decenio de 1990, en el 2002 el arancel medio en Centroamérica era de tan sólo 5,6\%, poco más de la mitad del promedio observado en América Latina (cuadro 9). ${ }^{13}$ Existe además una gran cantidad de exoneraciones subjetivas y de bienes que se encuentran libres de aranceles, fenómeno asociado fundamentalmente a los regímenes de promoción, incluidos los de zonas francas. Esto genera diversos problemas, como los de erosión de la base tributaria y de incentivo a la evasión.

\footnotetext{
${ }^{13}$ El MCCA hace que la variación del arancel promedio entre países sea mínima.
} 
El fortalecimiento de la integración subregional y de los tratados comerciales con terceros países hace prever que la tendencia hacia la desgravación arancelaria continuará, lo que en el futuro hará depender la recaudación tributaria casi exclusivamente de los impuestos internos. Como consecuencia, la administración tributaria se dificultará y será preciso introducir mejoras en las entidades recaudadoras.

\section{Efectos distributivos de los sistemas tributarios}

Para determinar el impacto de los impuestos sobre la distribución del ingreso es preciso realizar un análisis de incidencia sustentado en una cantidad significativa de información desagregada por deciles o quintiles de ingreso (distribución de ingresos y consumos, fuentes de ingresos, definición de la unidad familiar, etc.) y en elasticidades de la oferta y la demanda de los bienes de consumo y de los factores productivos. Tal información no siempre se encuentra disponible.

Además, hay que formular una serie de supuestos, como los referidos a la traslación de los gravámenes. En el caso de los impuestos directos sobre las personas físicas, por ejemplo, se supone en general que su percusión (o sea, su impacto directo) y su incidencia (su efecto de última instancia) recaen sobre el mismo contribuyente. No sucede lo mismo con los tributos indirectos, donde la traslación del impuesto es la regla. ${ }^{14}$
El cuadro 10 resume los resultados obtenidos en los estudios nacionales que se hicieron para tres países de la subregión. En él se aprecia que, en términos porcentuales, el coeficiente de Gini después de impuestos es mayor que antes de impuestos en los tres países para los cuales se dispone de información, lo que indica que los sistemas tributarios aumentan la concentración del ingreso. En el caso de Costa Rica, el efecto del sistema tributario sobre la distribución del ingreso en el 2000 es marginal.

\begin{tabular}{llcc} 
CUADRO 10 & \multicolumn{3}{c}{$\begin{array}{l}\text { Países centroamericanos (tres): Coeficientes } \\
\text { de Gini de distribución del ingreso } \\
\text { después de impuestos, 2000 }\end{array}$} \\
\hline País & Cobertura & $\begin{array}{c}\text { Coeficiente de } \\
\text { Gini antes } \\
\text { de impuesto }\end{array}$ & $\begin{array}{c}\text { Coeficiente de } \\
\text { Gini después } \\
\text { de impuestos }\end{array}$ \\
\hline Costa Rica & $\begin{array}{l}\text { Impuestos } \\
\text { nacionales }\end{array}$ & 0,482 & 0,483 \\
El Salvador & $\begin{array}{l}\text { Impuestos } \\
\text { nacionales }\end{array}$ & 0,502 & 0,517 \\
Honduras & $\begin{array}{l}\text { Impuestos } \\
\text { nacionales y } \\
\text { municipales }\end{array}$ & 0,543 & 0,571 \\
\hline
\end{tabular}

Fuente: Agosin, Barreix y Machado (2005); Bolaños (2002).

a Los cálculos de los coeficientes de Gini se basan en deciles de hogares.

\section{III}

\section{Recomendaciones en materia de reforma tributaria}

Tras haber identificado las razones para efectuar la reforma tributaria y descrito los sistemas impositivos centroamericanos en las secciones anteriores, es posible inferir los aspectos que deberían considerar las reformas tributarias que efectúen en el futuro los países de la subregión.

\footnotetext{
${ }^{14}$ El grado de traslación depende de las elasticidades-precio de la demanda y la oferta.
}

\section{El objetivo central: aumentar la recaudación para invertir en la gente}

Todas las recomendaciones que se hacen en este trabajo van en la dirección de acrecentar la carga tributaria con el propósito de que los gobiernos de la región cuenten con mayores recursos para invertir en el desarrollo humano. Esto es congruente con el objetivo de largo plazo de todos los países centroamericanos: acelerar el crecimiento y, a la vez, mejorar la distribución del ingreso. 
Cuando se busca aumentar la presión tributaria, más que incrementar tasas es preciso ampliar las bases imponibles de los tributos y fortalecer la administración tributaria. Con estas medidas se logrará también mejorar la elasticidad del sistema tributario ante cambios en el ingreso.

Para modernizar los sistemas tributarios se necesita un adecuado balance entre la imposición directa e indirecta, que permita dar forma a un sistema tributario sustentado en pocos tributos, que tengan bases imponibles amplias y generales y tasas moderadas. Hay que realizar significativos esfuerzos, dirigidos a ampliar no sólo la base imponible del IVA sino también la del impuesto sobre la renta de las personas y el impuesto sobre la renta de las sociedades, eliminando exenciones y desgravaciones que se traducen en un trato desigual a los distintos contribuyentes.

Muchos de los cambios que podrían introducirse, y que se han denominado de segunda generación en reconocimiento a las dificultades existentes para llevarlos a cabo, forman parte de un proceso cuyos resultados solo se observarán con el tiempo. Es por ello que el programa de reformas deberá arbitrar entre las necesidades inmediatas de recursos y las reformas de tipo estructural de mediano y largo plazo.

Es de suma importancia comenzar a cuantificar la pérdida que cada uno de los regímenes de incentivos implica para el fisco y, por lo tanto, el costo de oportunidad que ellos tienen. Esto implica realizar estudios de gasto tributario en todos los países de la subregión. Además, el conocimiento profundo de esa información permitirá identificar a los beneficiarios de los gastos tributarios, a los sectores promovidos y a los bienes y servicios alcanzados, con lo cual se podría superar el análisis exclusivo del costo fiscal de las medidas para ahondar en los efectos económicos de esas políticas.

\section{La necesidad de coordinación subregional}

Es urgente delinear un conjunto de parámetros o criterios básicos dentro de los cuales cada país centroamericano tendría la libertad de optar, dependiendo de sus circunstancias particulares. En ese sentido, uno de los primeros objetivos debería ser el de evitar las guerras fiscales dentro de la subregión, ya que ellas conducen inexorablemente a una degradación de los sistemas impositivos. La coordinación regional debería incluir tanto el establecimiento de pautas de referencia en materia de incentivos tributarios y de límites a la gravación selectiva de algunos bienes, como criterios para determinar las bases imponibles del IVA y del impuesto sobre la renta. En este último aspecto, sería muy conveniente que la subregión como un todo (quizás en el contexto de su TLC con los Estados Unidos) negociara un acuerdo tributario con este último país y adoptara normativas sobre precios de transferencia. ${ }^{15}$

\section{Opciones de reforma a los impuestos sobre la renta y sobre el patrimonio}

El análisis de los impuestos sobre la renta de las personas y sobre la renta de las sociedades deberá estar presente en el debate acerca de las opciones de reforma. Como ya se señaló, la distribución del ingreso personal o familiar en la subregión muestra una marcada concentración, que se ve incluso acentuada por los sistemas tributarios. Aunque la política tributaria no es el instrumento más apropiado para modificar esa distribución antes de impuestos, resulta difícil aceptar el impacto regresivo de los tributos.

Cabe mencionar, además, que las dificultades para administrar y fiscalizar con eficiencia los impuestos sobre la renta y sobre el patrimonio son más complejas que en el caso de los gravámenes directos. Por ello se requiere acrecentar los esfuerzos en esta materia, así como avanzar en la generalización de los sistemas de retención en la fuente pagadora como una manera de complementar la acción del Estado.

En cuanto al impuesto sobre la renta de las sociedades, el análisis de la situación existente en los países centroamericanos indica que el potencial recaudatorio de dicho impuesto no ha sido explotado adecuadamente, debido a las limitaciones que tiene la base imponible del tributo para captar los cambios económicos ocurridos en estos países. Aunque en los últimos años ha habido avances sustanciales en la estructura de las tasas, al convertir en tasas proporcionales las inconvenientes tasas progresivas utilizadas para gravar la renta empresarial, aún hace falta modernizar y generalizar las bases imponibles. La propuesta de reforma elaborada en Costa Rica a fines del 2001 va en esa dirección, aunque no sin dificultades para su aprobación parlamentaria.

Sería conveniente retomar la aplicación de impuestos mínimos sobre la renta presunta establecida en función del valor de los activos o de las ventas brutas. Esto contribuiría a cerrar la brecha de financiamiento y a fortalecer la tributación directa mientras se logra

\footnotetext{
${ }^{15}$ Las reglas del Internal Revenue Service de Estados Unidos son un modelo que podría ser emulado.
} 
poner en práctica efectivamente las reformas de fondo. En lo que se refiere al IRP, es conveniente avanzar hacia un esquema de impuesto sobre la renta global, reconociendo que la administración de dicho tributo es bastante más compleja que la de los actuales impuestos cedulares.

\section{Mejorar la administración tributaria}

Habrá que redoblar los esfuerzos por mejorar sustancialmente la eficacia y eficiencia de la administración tributaria y aduanera. De no hacerlo, ninguna reforma tributaria tendrá éxito. Se debe comenzar con la rápida sanción de códigos tributarios modernos que establezcan claramente los derechos y obligaciones de las partes involucradas, con el propósito de darle certeza, objetividad y transparencia a la relación fiscocontribuyente.

Asimismo, por el alto grado de concentración de las economías y las falencias de las administraciones tributarias, es preciso establecer criterios de diferenciación en materia impositiva según el tamaño y características de los contribuyentes. No es conveniente sujetar a los mismos criterios y normas administrativas a

APÉNDICE

Estimaciones econométricas

En el modelo estimado las variables fiscales normalizadas por el PIB están explicadas adecuadamente por el PIB per cápita y la distribución del ingreso (coeficiente de Gini). Las hipótesis, expuestas en el texto, son dos: i) la recaudación tributaria y los gastos públicos, como proporción del PIB, varían en relación directa con el ingreso per cápita y ii) varían en relación inversa con la desigualdad en la distribución del ingreso. Los resultados, que se calcularon para fines del decenio de 1990 con datos del Banco Mundial (2004), se pueden resumir de la siguiente manera:

$$
T / Y=\underset{(0,18)}{1,45}+\underset{(5,20)^{* *}}{3,97 \log Y P C}-\underset{(-4,93)^{* *}}{0,36 \text { GINI }}
$$

$\mathrm{R}^{2}$ ajustado $=0,469$; número de observaciones $=95$. Las cifras entre paréntesis corresponden al estadístico $t$; un asterisco indica que el coeficiente es estadísticamente significativo al $5 \%$ de confianza y dos asteriscos que lo es al $1 \%$ de confianza.

$$
\begin{aligned}
G / Y= & 19,50+2,66 \log Y P C-0,36 \text { GINI } \\
& (2,42)^{*}(3,57)^{* *} \quad(-4,42)^{* *}
\end{aligned}
$$

$\mathrm{R}^{2}$ ajustado $=0,307 ;$ número de observaciones $=120$. los contribuyentes grandes y a los pequeños. Las normas relativas a estos últimos deberán adecuarse tomando en cuenta su importante significación numérica y su bajo impacto recaudatorio. Por lo tanto, convendría instrumentar un sistema de declaración y pago simplificado para la microempresa y la pequeña empresa que incluya el IVA, el impuesto sobre la renta y, de ser el caso, aportes a la seguridad social, facilitando la administración y reduciendo los costos de cumplimiento y la informalidad.

Igualmente, debería acentuarse la tendencia a eliminar pequeños impuestos, tasas, derechos, contribuciones y patentes. Estos pequeños tributos tienen poco rendimiento, y obligan a movilizar gran cantidad de personas y de papeles que distraen al fisco de sus objetivos centrales.

Finalmente, habría que fortalecer las instancias de apelación ante decisiones administrativas, como son los tribunales fiscales. Este tipo de apelación, separada del aparato administrativo, contribuiría a facilitar la implementación de sistemas expeditos que permitan validar la deuda tributaria determinada por la administración y a la vez proteger los derechos del contribuyente.

$$
\begin{aligned}
G S A L / Y= & -4,36+1,10 \log Y P C-0,039 \text { GINI } \\
& (-3,54)^{* *}(9,67)^{* *}(-3,19)^{* *}
\end{aligned}
$$

$\mathrm{R}^{2}$ ajustado $=0,555 ;$ número de observaciones $=121$.

$$
G E D / Y=\begin{gathered}
0,74+0,54 \log Y P C-0,02 \text { GINI } \\
(0,44)(3,49)^{* *} \quad(-1,12)
\end{gathered}
$$

$\mathrm{R}^{2}$ ajustado $=0,138 ;$ número de observaciones $=120$.

La definición de las variables es la siguiente:

$$
\begin{aligned}
T / Y & =\text { ingresos tributarios, como proporción del PIB }(Y) \\
Y P C & =\text { PIB per cápita } \\
G I N I & =\text { coeficiente de Gini de distribución del ingreso } \\
G / Y & =\text { gasto público total, como proporción del PIB } \\
G S A L / Y= & \text { gasto público en salud, como proporción del PIB } \\
G E D / Y= & \text { gasto público en educación, como proporción } \\
& \text { del PIB. }
\end{aligned}
$$

El PIB per cápita aparece en todas las ecuaciones como altamente significativo para explicar las variaciones de las variables fiscales. Por otra parte, el coeficiente de Gini también es significativo en todas las ecuaciones, salvo la ecuación (4), 
que explica las variaciones entre países del gasto público en educación. Desde luego, este modelo es extremadamente parsimonioso. También se intentó incluir una variable que midiera la riqueza en recursos naturales (exportaciones de minerales como proporción de las exportaciones totales), pero ella no resultó ser significativa. La posible endogeneidad del coeficiente de Gini con respecto al PIB per cápita (como lo sugiere la U invertida de Kuznets) no produce problemas de multicolinealidad que invaliden los resultados obtenidos.

\section{Bibliografía}

Agosin, M.R., R. Machado y P. Nazal (comps.) (2004): Pequeñas economías, grandes desafíos: políticas económicas para el desarrollo en Centroamérica, Washington, D.C., Banco Interamericano de Desarrollo.

Agosin, M.R., A. Barreix y R. Machado (2005): Recaudar para crecer: bases para la reforma tributaria en Centroamérica, Washington, D.C., Banco Interamericano de Desarrollo.

Agosin, M. R. y E. Rodríguez (2005): Libre comercio en América Central: ¿Con quién y para qué?, Serie de estudios económicos y sectoriales, RE2-05-003, Washington, D.C., Banco Interamericano de Desarrollo.

Alesina, A. y D. Rodrik (1994): Distributive politics and economic growth, The Quarterly Journal of Economics, vol. 109, $\mathrm{N}^{\circ} 2$, Cambridge, Massachusetts, The MIT Press.

Arias, L.A., A. Barreix y otros (2005): La armonización de los impuestos indirectos en la Comunidad Andina, Buenos Aires, Banco Interamericano de Desarrollo/Instituto para la Integración de América Latina y el Caribe (INTAL), febrero.

Banco Mundial (2004): Indicadores del desarrollo mundial, Washington, D.C.

Barreix, A., J. Roca y L. Villela (2004): Integración y comercio en América. Impacto fiscal de la liberalización comercial en América, Nota periódica, Washington, D.C., Banco Interamericano de Desarrollo, enero.

Bolaños, R. (2002): Eficiencia y equidad en el sistema tributario costarricense, El sistema tributario costarricense. Contribuciones al debate nacional, San José, Contraloría General de la República.

Edwards, S. y R. Vergara (2002): Fiscal Sustainability, Debt Dynamics and Debt Relief: The Cases of Nicaragua and Honduras, Serie de estudios económicos y sectoriales, Washington, D.C., Banco Interamericano de Desarrollo.
Engel, E., A. Galetovic y C. E. Raddatz (1999): Taxes and income distribution in Chile: some unpleasant redistributive arithmetic, Journal of Development Economics, vol. 59, № 1, Amsterdam, Elsevier Science.

Hathaway, D. (2003): The impacts of U.S. agricultural and trade policy on liberalization and integration via a U.S.-Central American Free Trade Agreement, Special Initiative on Trade and Integration, Working Paper, SITI-04, Washington, D.C., Banco Interamericano de Desarrollo.

Houghton, J. (2004): An assessment of tax and expenditure incident in Peru, Boston, Suffolk University/Beacon Hill Institute for Public Policy, diciembre, inédito.

Jenkins, G. y C.Y. Kuo (2004): Is the VAT regressive in the Dominican Republic?, diciembre, inédito.

PNUD (Programa de las Naciones Unidas para el Desarrollo) (2000): Informe de desarrollo humano, 2000: Honduras, Tegucigalpa.

Rodríguez, A. y E. Robles (2003): Inversión nacional y extranjera en Centroamérica: ¿Cómo fomentarla en el marco de la OMC?, Proyecto Centroamérica en la economía mundial del Siglo XXI, Ciudad de Guatemala.

Sen, A. (1999): Development as Freedom, Nueva York, Basic Books. Stotsky, J. y A. WoldeMariam (2002): Central American Tax Reform: Trends and Possibilities, Working Paper, $\mathrm{N}^{\circ} \mathrm{WP} / 02 / 227$, Washington, D.C., Fondo Monetario Internacional, diciembre.

Todd, J., P. Winters y D. Arias (2004): CAFTA and the Rural Economies of Central America: a Conceptual Framework for Policy and Program Recommendations, Serie de estudios económicos y sectoriales, RE2-04-016, Washington, D.C., Banco Interamericano de Desarrollo.

Vergara, R. (2003): Sostenibilidad fiscal: El caso de El Salvador, Washington, D.C., Banco Interamericano de Desarrollo, inédito. 